\title{
AN INTERLABORATORY PHOTOMETRIC COMPARISON OF GLASS SCREENS AND OF TUNGSTEN LAMPS, INVOLVING COLOR DIFFERENCES
}

\author{
By G. W. Middlekauff and J. F. Skogland
}

\section{CONTENTS}

Page

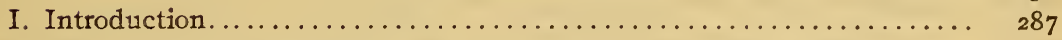

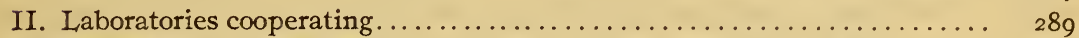

III. Screens, lamps, and instructions as to methods of measurement...... 289

IV. Results on the screens. . . . . . . . . .

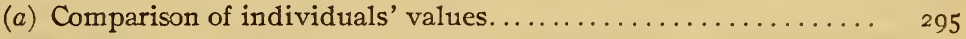

(b) Comparison of laboratories' values.................. 296

V. Results on the lamps. ............................ 297

VI. Comparison of results on lamps and screens................ 300

VII. Additional check measurements................. 30 I

VIII. Characteristics of Bureau of Standards' observers. . . . . . . . . . . . 303

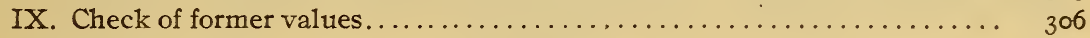

X. Conclusion. ..................... $30^{2} 7$

\section{INTRODUCTION}

Since the establishment of the international candle in 1909 this unit has been maintained at the Bureau of Standards solely by means of a group of 4 -wpc carbon filament incandescent lamps. With the advent of the tungsten lamp there was introduced into standardization work the difficulty of comparing lights of different colors, and at once it became desirable to have the unit well established also in tungsten lamps operated at or near their normal color.

In I9II, by common agreement between the National Physical Laboratory of England and the Bureau of Standards, each laboratory prepared a group of tungsten standards calibrated for voltage corresponding to approximately $\mathrm{I} .5 \mathrm{wpc}$. These two groups of lamps, which were thus operated at very approximately the same color, were then exchanged and each group was remeasured by the receiving laboratory at the voltage determined by the sending laboratory. A group, similar to the one sent to England, and standardized in the same series of measurements, 
was retained at the Bureau, and half of the group received from England, after measurement, was returned for remeasurement.

In view of the difficulties involved in the intercomparison, the result was very satisfactory, as it showed that the two laboratories were in agreement to within the indicated precision of the measurements. In both laboratories the new standards were measured by means of Lummer-Brodhun contrast photometers of the standard type, and in terms of similar groups of 4 -wpc carbon standards, the English laboratory having made the comparison by the cascade method, ${ }^{1}$ the Bureau of Standards by the use of two calibrated blue glass screens, each of which produced a color match between the two groups of standards compared. It is obvious, therefore, that the calibration of the glass screens used by the Bureau in this intercomparison was a matter of prime importance, and for this reason a large amount of work has been done in checking, by various methods, the values first assigned.

In connection with these check measurements and after a determination of the candlepower and current of a group of tungsten substandards at several voltages had been made, and this followed by a further investigation of other groups of tungsten lamps, the voltage-current-candlepower curves were determined and accurately expressed by means of equations. ${ }^{2}$ It was found that by employing these equations it is possible to measure tungsten lamps in color match with 4-wpc carbon standards and compute with accuracy their value at any other color within the range investigated. In this way, as well as by direct comparisons, the new tungsten standards have been rechecked a number of times by different groups of observers.

These equations have an important application also in the life testing of tungsten lamps, because in some testing laboratories it is customary to photometer the lamps at or near rated voltage and compute the voltage corresponding to the efficiency at which it is desired to burn the lamps on life test.

In the establishment of the I.5-wpc tungsten standards and also in the determination of the characteristic equations, the photometric measurements of necessity involved color differences. Although numerous check measurements have been made and the results have been very satisfactory, it is, of course, realized

${ }_{1}$ Paterson and Dudding, Proc. Phys. Soc. London,. p. $26_{3}$, Apr. 15, 1915; also Phil. Mag., p. 63, July, I915.

2 Middlekauff and Skogland, Characteristic Equations of Tungsten Filament Lamps and their Application in Heterochromatic Photometry, Trans. I. E. S. 9, p. 734, rgr4; also this Bulletin, 11, p. 483, r9r5. 
that if some other group of observers had made these measurements the values obtained might have been different.

It was therefore suggested that an interlaboratory photometric comparison of lights involving color differences such as those encountered in these measurements would yield valuable information not only as to the agreement which might be reasonably expected among different groups of experienced observers, but also information as to the merits of different methods of making such measurements.

\section{LABORATORIES COOPERATING}

The Bureau, therefore, in May, I9r4, invited several of the more important photometric laboratories of the country to cooperate with it in making measurements of this kind.

Through Dr. E. P. Hyde, Dr. C. H. Sharp, and Dr. H. E. Ives, respectively, the Nela Research Laboratory, the Electrical Testing Laboratories, and the Physical Laboratory of the United Gas Improvement Co. kindly agreed to make such measurements on glass screens and tungsten lamps as the Bureau would direct.

\section{SCREENS, LAMPS, AND INSTRUCTIONS AS TO METHODS OF MEAS- UREMENT}

For this intercomparison there were selected three blue glass screens of different color densities and marked $2 \mathrm{~B}, 2 \mathrm{~T} / 2 \mathrm{~B}$, and $3 \mathrm{~B}$, respectively. $2 \mathrm{I} / 2 \mathrm{~B}$ was of approximately the same color density as the screens used by the Bureau in the intercomparison with England, and was therefore such as to produce a color match between the 4-wpc carbon standards and the I.5-wpc tungsten standards. $2 \mathrm{~B}$ and $3 \mathrm{~B}$ were of lesser and greater color density, respectively, than $2 \frac{1}{2} \mathrm{~B}$, producing a color match between the 4wpc carbon standards and tungsten lamps at about $\mathrm{I} .9 \mathrm{wpc}$ and I. $25 \mathrm{wpc}$, respectively.

The transmission of each glass for light of 4-wpc carbon color was to be determined by each laboratory, and, in order that the proper color might be used, a carbon standard of this color at a specified voltage was sent along with the screens.

There were selected also four tungsten standards to be measured for candlepower and current at several specified voltages, the color at the lowest voltage being the same as that of the 4wpc carbon standards. The candlepower at the other voltages was to be determined in terms of the value at the lowest voltage taken as standard, or unity. 
The voltages specified for these measurements corresponded to a range from 3.I wpc to $0.85 \mathrm{wpc}$ for the tungsten lamp. The lamps were selected from those used in the investigation of the characteristic curves and included a 6o-watt sintered filament lamp (No. 2608); a 60-watt "formed" drawn-wire lamp (No. 2662) with spring anchors; and two 40-watt drawn-wire lamps (Nos. 2865 and 2866).

As the purpose of the investigation was to obtain information as to methods and the agreement of different groups of observers in passing from one color to another in photometric measurements, no instructions other than those mentioned above were issued to the laboratories. It was desired that each laboratory proceed by the method it considered best, and it was not expected that a large number of measurements would be made. Hence, in view of the difficulties which were to be met in these measurements, it was hardly to be expected that values established by the Bureau as the result of a much larger number of measurements and checks would be repeated exactly. However, as will appear later, the results of all the laboratories are extremely consistent and the agreement quite satisfactory.

Two of the laboratories (E. T. L. and N. R. L.) used standard type Lummer-Brodhun contrast photometers in all the measurements. The third laboratory (U. G. I.), in the measurements on the screens, used a special flicker photometer, ${ }^{3}$ and in the measurements on the lamps a Lummer-Brodhun photometer having in the eyepiece a cell containing a Crova solution ${ }^{4}$ which was calibrated by a method involving the flicker photometer. All the measurements by the U. G. I. were made under selected conditions of illumination and with groups of observers selected after tests of their color vision with respect to the average of much larger groups. The data obtained are therefore valuable in making a comparison, not only of observers but also of different methods of measurement.

In no laboratory were the lamps measured at the same time as the screens, a period of from 4 to I 3 months having intervened between the two series. ${ }^{5}$ Although this was not intentional, it fortunately proved of value in showing that each laboratory consistently maintained its criterion in measurements involving a

\footnotetext{
${ }^{3}$ H. E. Ives, Phys. Rev., p. 222; Sept., I9I4.

4 Ives and Kingsbury; Trans. I., E. S., 10, p. 716; I915.

5 The intercomparison was begun in June, 1914, but was not completed until in December, I9I5.
} 
color difference. In order to avoid confusion, all the results, including those of the Bureau, on the screens are given together, as are likewise ine results on the lamps.

\section{RESULTS ON THE SCREENS}

The values for the screens are given in the four following tables, and, except as noted, they are as stated in the reports from the laboratories. The results of the three laboratories using LummerBrodhun photometers are grouped together, and when comparisons are made, flicker values are compared with the mean of those obtained with the Lummer-Brodhun.

\section{TABLE 1}

Values of Transmission-Bureau of Standards

\begin{tabular}{|c|c|c|c|c|c|c|}
\hline \multirow{2}{*}{ Observers } & \multicolumn{2}{|c|}{$2 \mathrm{~B}$} & \multicolumn{2}{|c|}{$21 / 2 \mathrm{~B}$} & \multicolumn{2}{|c|}{ 3B } \\
\hline & $\begin{array}{l}\text { Indirect } \\
\text { method }\end{array}$ & $\begin{array}{c}\text { Direct } \\
\text { method }\end{array}$ & $\begin{array}{l}\text { Indirect } \\
\text { method }\end{array}$ & $\begin{array}{l}\text { Direct } \\
\text { method }\end{array}$ & $\begin{array}{l}\text { Indirect } \\
\text { method }\end{array}$ & $\begin{array}{l}\text { Direct } \\
\text { method }\end{array}$ \\
\hline G. W. M... & 0.652 & 0.654 & 0.585 & 0.588 & 0.537 & 0.542 \\
\hline J. F.S...................... & .651 & .652 & .585 & .584 & .538 & .538 \\
\hline B. M.............. & .648 & .645 & .581 & .575 & .541 & .526 \\
\hline H. B. S.......... & .652 & .667 & (a) & .596 & (a) & .552 \\
\hline w. J. K........ & .652 & .652 & .585 & .580 & .539 & .534 \\
\hline 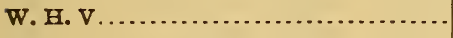 & .651 & .648 & .581 & .581 & .535 & .535 \\
\hline 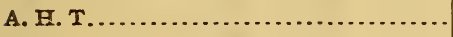 & .651 & .655 & .584 & .583 & .541 & .535 \\
\hline G. J.S........... & .650 & .652 & .585 & .582 & .538 & .536 \\
\hline Mean. & .651 & .653 & .584 & .584 & .538 & .537 \\
\hline
\end{tabular}

a Observer not available.

The photometer used was the standard Lummer-Brodhun contrast. The approximate illumination on the photometer screen was io meter-candles.

METHODS.- I. Direct Method.-The screen was placed on the test side of the photometer, the test lamp (a tungsten) was set to 4-wpc carbon color, and the comparison lamp (also a tungsten) was adjusted to match in color the light transmitted by the screen. Photometric settings were made first with the screen in place, then with it removed, there being a color difference under the latter condition. The ratio of the first settings to the second gave the transmission of the screen.

2. Indirect Method.-The first settings were made as in the direct method, but when the screen was removed the test lamp 
was sufficiently increased in voltage to produce a color match with the comparison lamp. The ratio of the candlepower of the test lamp at these two voltages was computed by means of the voltage-candlepower equation. With this factor applied, the ratio of the settings, screen in to screen out, gave the transmission.

In both of the above methods, when the screen was removed it was replaced by a rotating sectored disk of the proper opening to make the photometer balance at about the same point as when the screen was in place.

Each value in Table $I$ is the mean of about four independent determinations, the average deviation, by either method, being about 0.5 per cent.

\section{TABLE 2}

Values of Transmission-Electrical Testing Laboratories

\begin{tabular}{|c|c|c|c|c|c|c|c|c|c|}
\hline \multirow{2}{*}{ Observers } & \multicolumn{3}{|c|}{$2 \mathrm{~B}$} & \multicolumn{3}{|c|}{$21 / 2 B$} & \multicolumn{3}{|c|}{$3 \mathrm{~B}$} \\
\hline & $\underset{1}{\text { Series }}$ & $\begin{array}{c}\text { Series } \\
2\end{array}$ & $\underset{\text { mean }}{\text { Weighted }}$ & $\begin{array}{c}\text { Series } \\
1\end{array}$ & $\begin{array}{c}\text { Series } \\
2\end{array}$ & $\begin{array}{c}\text { Weighted } \\
\text { mean }\end{array}$ & $\begin{array}{c}\text { Series } \\
1\end{array}$ & $\begin{array}{c}\text { Series } \\
2\end{array}$ & $\begin{array}{l}\text { Weighted } \\
\text { mean }\end{array}$ \\
\hline C. H. S. & 0.651 & …... & 0.651 & 0.583 & ..... & 0.583 & 0.537 & ... & 0.537 \\
\hline W.F.L. & .660 & 0.672 & .666 & .594 & 0.586 & .590 & .530 & 0.553 & .542 \\
\hline M. H. T... & .660 & .662 & .661 & .585 & .588 & .586 & .545 & .546 & .545 \\
\hline C. E. H.... & .656 & .652 & .655 & .586 & .587 & .586 & .545 & .537 & .542 \\
\hline W. A.M.... & .656 & .657 & .656 & .587 & .576 & .583 & .543 & .539 & .542 \\
\hline Z.N.C... & .653 & ......... & .653 & .579 & $\cdots$. & .579 & .535 & $\cdots .$. & .535 \\
\hline A. $\mathrm{K} . . . \ldots$ & .659 & ......... & .659 & .589 & …... & .589 & .539 & ...... & .539 \\
\hline E. H... & $\cdots \cdots$ & .666 & .666 & .......... & .594 & .594 & ......... & .555 & .555 \\
\hline Mean... & .656 & .662 & . & .586 & .586 & & .539 & .546 & ...... \\
\hline Weighted mean. & .656 & .659 & .657 & .585 & .586 & .585 & .541 & .543 & .542 \\
\hline
\end{tabular}

The photometer used was the standard Lummer-Brodhun contrast. The approximate illumination on the photometer screen was 2.5 to 3.8 meter-candles. As the distance between test and comparison lamps was fixed, the illumination depended upon the screen used and was highest with the screen removed.

Method: Direct. - Two carbon lamps, each operated at a voltage giving a match in color with the B. S. 4-wpc carbon lamp, were set up at opposite ends of a five-meter photometer. Settings were made, first without the screen, then with the screen interposed. This was done first on one side of the photometer and then on the other. The observers were weighted according to their experience in color difference measurements and the number of measurements made in these tests. Series $I$ and 2 are independent 
determinations by this method. For purposes of comparison the weighted mean values (columns 4,7 , and 10) for each observer were computed by the authors.

TABLE 3

Values of Transmission-Nela Research Laboratory

\begin{tabular}{|c|c|c|c|c|c|c|c|c|c|}
\hline \multirow{2}{*}{ Observers } & \multicolumn{3}{|c|}{$2 \mathrm{~B}$} & \multicolumn{3}{|c|}{$21 / 2 B$} & \multicolumn{3}{|c|}{$3 B$} \\
\hline & Series 1 & Series 2 & Mean & Series 1 & Series 2 & Mean & Series 1 & Series 2 & Mean \\
\hline E. P. H. & 0.660 & 0.662 & 0.661 & 0.590 & 0.592 & 0.591 & 0.544 & 0.543 & 0.544 \\
\hline F.E. C.... & .659 & .661 & .660 & .592 & .590 & .591 & .548 & .546 & .547 \\
\hline M. L..... & .665 & .660 & .662 & .593 & .590 & .592 & .551 & .541 & .546 \\
\hline C. F.S..... & .652 & .650 & .651 & .578 & .578 & .578 & .531 & .530 & .531 \\
\hline R. G. B..... & .664 & .662 & .663 & .594 & .592 & .593 & .550 & .549 & .550 \\
\hline I. R. W.... & .656 & .656 & .656 & .584 & .584 & .584 & .540 & .538 & .539 \\
\hline Mean. & .659 & $.658_{5}$ & .659 & $.588_{5}$ & .588 & .588 & .544 & .543 & .543 \\
\hline
\end{tabular}

The photometer used was the standard Lummer-Brodhun contrast. The approximate illumination on photometer screen was I 7 meter-candles.

Method.-Same as the B. S. direct method; except that the screen and sectored disk were employed on the side of the comparison lamp, which was set to 4 -wpc carbon color. Series I . and 2 are independent determinations by this method.

TABLE 4

Values of Transmission-United Gas Improvement Co.

\begin{tabular}{|c|c|c|c|c|c|c|c|c|c|}
\hline \multirow{2}{*}{ Observers } & \multicolumn{3}{|c|}{$2 \mathrm{~B}$} & \multicolumn{3}{|c|}{$2 \frac{1}{2} \mathrm{~B}$} & \multicolumn{3}{|c|}{$3 B$} \\
\hline & $\begin{array}{c}\text { Series } \\
1\end{array}$ & $\begin{array}{c}\text { Series } \\
2\end{array}$ & Mean & $\begin{array}{c}\text { Series } \\
1\end{array}$ & $\begin{array}{c}\text { Series } \\
2\end{array}$ & Mean & $\begin{array}{c}\text { Series } \\
1\end{array}$ & $\begin{array}{c}\text { Series } \\
\end{array}$ & Mean \\
\hline H. E. I. & 0.645 & 0.650 & 0.6475 & 0.580 & 0.579 & 0.5795 & 0.534 & 0.527 & 0.5305 \\
\hline E. F. K... & .658 & .661 & .6595 & .587 & .588 & .5875 & .548 & .543 & .5455 \\
\hline F. A. S... & .645 & .646 & .6455 & .583 & .577 & .5800 & .528 & .523 & .5255 \\
\hline B. J........... & .656 & .642 & .6490 & .575 & .574 & .5745 & .528 & .528 & .5280 \\
\hline D. V. L. D... & .639 & .642 & .6405 & .585 & .578 & .5815 & .529 & .522 & .5255 \\
\hline E. J.B........ & .637 & .639 & .6380 & .572 & .573 & .5725 & .521 & .522 & .5215 \\
\hline W. M. W... & .640 & .643 & .6415 & .576 & .577 & .5765 & .521 & .528 & .5245 \\
\hline Mean.. & .646 & .646 & .646 & .580 & .578 & .579 & .530 & .528 & .529 \\
\hline
\end{tabular}

The photometer used was a special flicker (see footnote 3 ). The brightness of the photometer field was that of a magnesium oxide surface under 25 meter-candles illumination. 
Method: Direct.-The measurements were made by seven observers so selected from 25 that their mean on the color difference for which they were tested was the same as that of the 25 .

\section{TABLE 5}

\section{Deviations of Each Observer From the Mean of His Laboratory BUREAU OF STANDARDS}

Direct Method

\begin{tabular}{|c|c|c|c|c|c|c|c|c|c|}
\hline \multirow{2}{*}{ Observers } & \multicolumn{4}{|c|}{ Transmission } & \multicolumn{3}{|c|}{$\begin{array}{l}\text { Deviation of obscrvers } \\
\text { from mean of all }\end{array}$} & \multirow{2}{*}{$\begin{array}{l}\text { Mean } \\
\text { of } \\
\text { devia- } \\
\text { tions }\end{array}$} & \multirow{2}{*}{$\begin{array}{l}\text { Maxi- } \\
\text { mum } \\
\text { differ- } \\
\text { ence } \\
\text { be- } \\
\text { tween } \\
\text { devia- } \\
\text { tions }\end{array}$} \\
\hline & $2 \mathrm{~B}$ & $21 / 2 \mathrm{~B}$ & $3 B$ & Mean & $2 \mathrm{~B}$ & $21 / 2 \mathrm{~B}$ & $3 B$ & & \\
\hline G. W. M. & 0.654 & 0.588 & 0.542 & 0.595 & +0.001 & +0.004 & +0.005 & 0.003 & 0.004 \\
\hline J.F.S.......... & .652 & .584 & .538 & .592 & -.001 & .000 & +.001 & .001 & .002 \\
\hline B. M............ & .645 & .575 & .526 & .582 & -.008 & -.009 & -.011 & .009 & .003 \\
\hline H. B. S. . & .667 & .596 & .552 & .605 & +.014 & +.012 & +.015 & .014 & .003 \\
\hline W. J.K... & .652 & .580 & .534 & .589 & -.001 & -.004 & -.003 & .003 & .003 \\
\hline W. H. V.... & .648 & .581 & .535 & .588 & -.005 & -.003 & -.002 & .003 & .003 \\
\hline 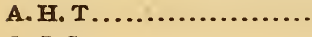 & .655 & .583 & .535 & .591 & +.002 & -.001 & -.002 & .002 & .004 \\
\hline G. J.S........................ & .652 & .582 & .536 & .590 & -.001 & -.002 & -.001 & .001 & .001 \\
\hline Mean.. & .653 & .584 & .537 & .591 & .004 & .004 & .005 & .004 & .003 \\
\hline
\end{tabular}

Indirect Method

\begin{tabular}{|c|c|c|c|c|c|c|c|c|c|}
\hline 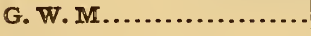 & 0.652 & 0.585 & 0.537 & 0.591 & +0.001 & +0.001 & -0.001 & 0.001 & 0.002 \\
\hline 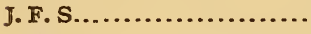 & .651 & .585 & .538 & .591 & .000 & +.001 & .000 & .000 & .001 \\
\hline B. M... & .648 & .581 & .541 & .590 & -.003 & -.003 & +.003 & .003 & .006 \\
\hline H. B. S.............. & .652 & …. & ...... & ..... & +.001 & ........ & ........ & ........ & $\ldots$. \\
\hline W. J. K ............... & .652 & .585 & .539 & .592 & +.001 & +.001 & +.001 & .001 & .000 \\
\hline W. H. V........... & .651 & .581 & .535 & .589 & .000 & -.003 & -.003 & .002 & .003 \\
\hline A. H. T. & .651 & .584 & .541 & .592 & .000 & .000 & +.003 & .001 & .003 \\
\hline 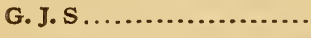 & .650 & .585 & .538 & .591 & -.001 & +.001 & .000 & .001 & .002 \\
\hline Mean ................ & .651 & .584 & .538 & .591 & .001 & .001 & .002 & .001 & .002 \\
\hline
\end{tabular}

ELECTRICAL TESTING LABORATORIES (Direct Method)

\begin{tabular}{|c|c|c|c|c|c|c|c|c|c|}
\hline C. H. S.. & 0.651 & 0.583 & 0.537 & 0.590 & -0.006 & -0.002 & -0.005 & 0.004 & 0.004 \\
\hline W. F.I . . . . . . . & .666 & .590 & .542 & .599 & +.009 & +.005 & .000 & .005 & .009 \\
\hline M. H. T... & .661 & .586 & .545 & .597 & +.004 & +.001 & +.003 & .003 & .003 \\
\hline C. E. $H \ldots \ldots$ & .655 & .586 & .542 & .594 & -.002 & +.001 & .000 & .001 & .003 \\
\hline W.A.M........ & .656 & .583 & .542 & .594 & -.001 & -.002 & .000 & .001 & .002 \\
\hline Z. N. C.... & .653 & .579 & .535 & .589 & -.004 & -.006 & -.007 & .006 & .003 \\
\hline A. $\mathbf{K} \ldots \ldots \ldots \ldots \ldots$ & .659 & .589 & .539 & .596 & +.002 & +.004 & -.003 & .003 & .007 \\
\hline E. H ........ & .666 & .594 & .555 & .605 & +.009 & +.009 & +.013 & .010 & .004 \\
\hline Mean & .657 & .585 & .542 & .595 & .005 & .004 & .004 & .004 & .004 \\
\hline
\end{tabular}


TABLE 5-Continued

Deviations of Each Observer From the Mean of His Laboratory-Continued

NELA RESEARCH LABORATORY (Direct Method)

\begin{tabular}{|c|c|c|c|c|c|c|c|c|c|}
\hline \multirow{2}{*}{ Observers } & \multicolumn{4}{|c|}{ Transmission } & \multicolumn{3}{|c|}{$\begin{array}{l}\text { Deviation of observers } \\
\text { from mean of all }\end{array}$} & \multirow{2}{*}{$\begin{array}{c}\text { Mean } \\
\text { of } \\
\text { devia- } \\
\text { tions }\end{array}$} & \multirow{2}{*}{$\begin{array}{l}\text { Maxi- } \\
\text { muma } \\
\text { differ- } \\
\text { ence } \\
\text { be- } \\
\text { tween } \\
\text { devia- } \\
\text { tions }\end{array}$} \\
\hline & $2 B$ & $2 \frac{1}{2} B$ & $3 \mathrm{~B}$ & Mean & $2 \mathrm{~B}$ & $21 / 2 B$ & $3 B$ & & \\
\hline E.P. H. & 0.661 & 0.591 & 0.544 & 0.599 & +0.002 & +0.003 & +0.001 & 0.002 & 0.002 \\
\hline F.E. C.. & .660 & .591 & .547 & .599 & +.001 & +.003 & +.004 & .003 & .003 \\
\hline M. L. & .662 & .592 & .546 & .600 & +.003 & +.004 & +.003 & .003 & .001 \\
\hline C. F.S. & .651 & .578 & .531 & .587 & -.008 & -.010 & -.012 & .010 & .004 \\
\hline R. G. B . & .663 & .593 & .550 & .602 & +.004 & +.005 & +.007 & .005 & .003 \\
\hline I. R. W.. & .656 & .584 & .539 & .593 & -.003 & -.004 & -.004 & .004 & .001 \\
\hline Mean. & .659 & .588 & .543 & .597 & .003 & .005 & .005 & .004 & .002 \\
\hline
\end{tabular}

UNITED GAS IMPROVEMENT CO. (Direct Method)

\begin{tabular}{|c|c|c|c|c|c|c|c|c|c|}
\hline H. E. I. . . . . . . . & 0.648 & 0.580 & 0.530 & 0.586 & +0.002 & +0.001 & +0.001 & 0.001 & 0.001 \\
\hline E. F. K... & .660 & .588 & .546 & .598 & +.014 & +.009 & +.017 & .013 & .008 \\
\hline F. A. S............. & .646 & .580 & .526 & .584 & .000 & +.001 & -.003 & .001 & .004 \\
\hline B. J........... & .649 & .574 & .528 & .584 & +.003 & -.005 & -.001 & .003 & .008 \\
\hline D. V.I. D.... & .640 & .582 & .526 & .583 & -.006 & +.003 & -.003 & .004 & .009 \\
\hline E. J. B.......... & .638 & .572 & .521 & .577 & -.008 & -.007 & -.008 & .008 & .001 \\
\hline W. M. W............. & .642 & .576 & .524 & .581 & -.004 & -.003 & -.005 & .004 & .002 \\
\hline Mean ................. & .646 & .579 & .529 & .585 & .005 & .004 & .005 & .005 & .005 \\
\hline
\end{tabular}

(a) Comparison of Individuals' Values.-Another statement of the results, including only the mean of the values obtained by each observer on each of the three screens, is given in Table 5. In the fifth column is given the mean of the values of each observer for the three glasses. In the sixth, seventh, and eighth columns are the deviations of each observer's value from the mean of his laboratory on each glass. The constancy of the ratio of an observer's determination to that of his laboratory shows the consistency with which he maintains his criterion throughout the range of color included. An examination of the deviations shown in this table (excluding for the present those of the Bureau by the indirect method) shows that practically every observer, irrespective of the kind of photometer used, maintained a fairly definite relation to the mean of the observers of his laboratory. An observer's agreement with himself is indicated by the differences given in the last column of the table. 
By the indirect method the variations among observers is avoided, the difficulties of measurements with a color difference having been previously met in the determination of the characteristic equation upon which, of course, the values obtained depend. As shown by the table, the deviations of all observers are about equal and about one-fourth what they are by the direct (color difference) method, although there is practically the same degree of agreement of an observer with himself. The chief advantage of this method in calibrating a screen is that a reliable result may be obtained by any group of observers, while by the direct method the results may be somewhat different, depending upon the characteristics of the observers.

(b) COMPARISON OF LABORATORIES' VALUES.-In order to show in the same way the agreement among the various laboratories, each taken as a unit, the final means for each laboratory are given in Table 6 , in which, as before, the flicker values are compared with the mean of those obtained with the LummerBrodhun photometer.

\section{TABLE 6}

Deviations of Laboratories' Values from the Mean of the Three Using LummerBrodhun Photometers

Lummer-Brodhun Photometer

\begin{tabular}{|c|c|c|c|c|c|c|c|c|c|}
\hline \multirow{2}{*}{ Laboratories } & \multicolumn{4}{|c|}{ Transmission } & \multicolumn{3}{|c|}{$\begin{array}{l}\text { Deviations from mean } \\
\text { L-B values }\end{array}$} & \multirow{2}{*}{$\begin{array}{c}\text { Mean } \\
\text { of } \\
\text { devia- } \\
\text { tions }\end{array}$} & \multirow{2}{*}{$\begin{array}{c}\text { Maxi- } \\
\text { mum } \\
\text { difference } \\
\text { between } \\
\text { devia- } \\
\text { tions }\end{array}$} \\
\hline & $2 B$ & $2 \mathrm{~T} / 2 \mathrm{~B}$ & $3 B$ & Mean & $2 \mathrm{~B}$ & $2 \pi / 2 B$ & $3 B$ & & \\
\hline B. S......... & 0.653 & 0.584 & 0.537 & 0.591 & -0.003 & -0.002 & -0.004 & 0.003 & 0.002 \\
\hline E.T. T.......... & .657 & .585 & .542 & .595 & +.001 & -.001 & +.001 & .001 & .002 \\
\hline N. R. L... & .659 & .588 & .543 & .597 & +.003 & +.002 & +.002 & .002 & .001 \\
\hline Mean. & .656 & .586 & .541 & .594 & .002 & .002 & .002 & .002 & .002 \\
\hline
\end{tabular}

Flicker Photometer

\begin{tabular}{l|l|l|l|l|l|l|l|l|r}
\hline U. G. I.................... & 0.646 & 0.579 & 0.529 & 0.585 & -0.010 & -0.007 & -0.012 & 0.010 & 0.005 \\
\hline
\end{tabular}




\section{RESULTS ON THE LAMPS}

The results on the lamps were expressed differently by each laboratory. One (E. T. L.) gave all the values in candlepower; another (U. G. I.) reported the values as ratios using the value at the lowest voltage as unity; and the third (N. R. L.) gave the ratio of the candlepower at each voltage to the candlepower at the next lower voltage. Only one laboratory (N. R. L.) reported the values of the individual observers as was done by all in their reports on the screens. For this reason only the mean values obtained by each laboratory are given in the table of results (Table 7).

The Bureau's values of both current and candlepower were read from the characteristic curves previously determined by a group of observers whose mean was practically the same as the mean of the group that made the measurements on the screens.

In the Electrical Testing Laboratories the candlepower measurements were made by two observers (M. H. T. and C. E. H.) whose mean was the same as the mean of all the observers on the screens and the color steps were made with Wratten filters which had been calibrated by a large number of observers. In the Nela Research Laboratory the measurements on the lamps and screens were made by the same group of observers with the exception that observer M. L. made no measurements on the lamps. The cascade method was used in determining values on the lamps at the various voltages.

In the U. G. I. Laboratory the lamps were measured with a Lummer-Brodhun photometer having in the eyepiece a Crova solution calibrated on the photometric scale there used in which are involved the flicker photometer under certain chosen illumination and other conditions and the selection of observers from a large group. The group used as a basis for the Crova solution work consisted of $6 \mathrm{r}$ observers; the glass screen calibrations were on the basis of a group of 25 
TABLE 7

Candlepower and Current Values Found by the Different Laboratories

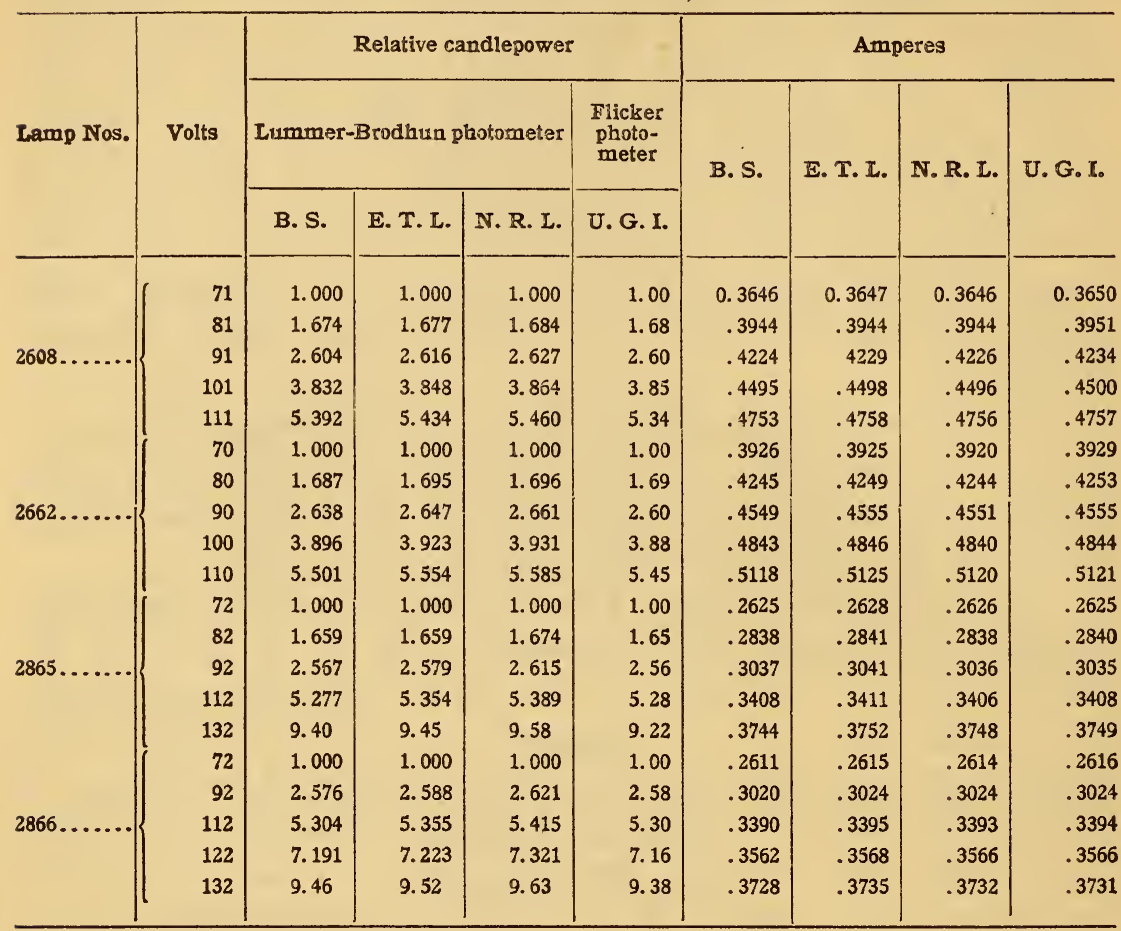

The Nela Research Laboratory gave the highest and lowest ampere values at each voltage, but to make the results uniform with the definite values reported by the other laboratories the mean of these extremes at each voltage was assumed as the correct ampere value. The deviations of the ampere values as given for the various laboratories in Table 7 from the mean of all at each voltage have been computed and found to be, on the average, about 0.05 per cent and the same for all four lamps.

In Table 8 are given the values of the ratios of the candlepower at each voltage to that at the lowest voltage, which corresponds to 4 -wpc carbon color. The laboratories are arranged in the order in which they measured the lamps. As in the case of the results on the glass screens, the values obtained by each laboratory are compared with the mean of the three laboratories using Lummer-Brodhun photometers. 
TABLE 8

Comparison of Candlepower Ratios Found by the Different Laboratories

\begin{tabular}{|c|c|c|c|c|c|c|}
\hline \multirow{3}{*}{ Lamp Nos. } & \multirow{3}{*}{$\begin{array}{l}\text { Voltage } \\
\text { ratio }\end{array}$} & \multicolumn{5}{|c|}{ Candlepower ratio } \\
\hline & & \multicolumn{4}{|c|}{ Lummer-Brodhun photometer } & \multirow{2}{*}{$\begin{array}{c}\begin{array}{c}\text { Flicker } \\
\text { photo- } \\
\text { meter }\end{array} \\
\text { U. G. I. }\end{array}$} \\
\hline & & B. S. & E.T. L. & N. R. L. & Mean & \\
\hline 2608. & $81: 71$ & 1.674 & 1.677 & 1.684 & 1.678 & 1.68 \\
\hline $2662 \ldots$ & $80: 70$ & 1.687 & 1.695 & 1.696 & 1.693 & 1.69 \\
\hline $2865 \ldots \ldots \ldots$ & $82: 72$ & 1.659 & 1.659 & 1.674 & 1.664 & 1.65 \\
\hline Mean. & . & 1.673 & 1.677 & 1.685 & 1.678 & 1.673 \\
\hline Deviation from mean (per cent). & …... & -.3 & -.1 & +.4 & .3 & -.3 \\
\hline $2608 .$. & $91: 71$ & 2.604 & 2.616 & 2.627 & 2.616 & 2.60 \\
\hline 2662. & $90: 70$ & 2.638 & 2.647 & 2.661 & 2.649 & 2.60 \\
\hline $2865 \ldots \ldots \ldots$ & $92: 72$ & 2.567 & 2.579 & 2.615 & 2.587 & 2.56 \\
\hline $2866 \ldots . . . \ldots \ldots . . .$. & $92: 72$ & 2.576 & 2.588 & 2.621 & 2.595 & 2.58 \\
\hline Mean.. & & 2.596 & 2.608 & 2.631 & 2.612 & 2.585 \\
\hline Deviation from mean (ger cent)... & ........ & -.6 & -.2 & +.7 & .5 & -1.0 \\
\hline 2608. & $101: 71$ & 3.832 & 3.848 & 3.864 & 3.848 & 3.85 \\
\hline 2662. & $100: 70$ & 3.896 & 3.923 & 3.931 & 3.917 & 3.88 \\
\hline Mean. & $\cdots . .$. & 3. 864 & 3.880 & 3.898 & 3.883 & 3.865 \\
\hline Deviation from mean (per cent). & .......... & -.5 & +.1 & +.4 & .3 & -.5 \\
\hline 2608. & $111: 71$ & 5.392 & 5.434 & 5.460 & 5.429 & 5.34 \\
\hline $2662 \ldots$ & $110: 70$ & 5.501 & 5.554 & 5.585 & 5.547 & 5.45 \\
\hline 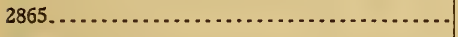 & $112: 72$ & 5.277 & 5.354 & 5.389 & 5.340 & 5.28 \\
\hline 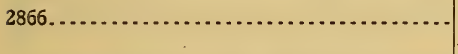 & $112: 72$ & 5.304 & $\begin{array}{r}5.355 \\
-\end{array}$ & 5.415 & 5.358 & 5.30 \\
\hline Mean.. & -... & 5.368 & 5.424 & 5.462 & 5.418 & 5.342 \\
\hline Deviation from mean (per cent). & …… & -.9 & $\begin{array}{l}+.1 \\
\end{array}$ & +.8 & .6 & -1.4 \\
\hline $2866 \ldots$ & $122: 72$ & 7.191 & 7.223 & 7.321 & 7.245 & 7.16 \\
\hline Deviation from mean (per cent).. & - n........ & -.7 & 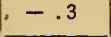 & +1.0 & .7 & -1.2 \\
\hline $2865 \ldots$ & $132: 72$ & 9.40 & 9.45 & 9.58 & 9.48 & 9.22 \\
\hline $2865 \ldots$ & $132: 72$ & 9.46 & 9.52 & 9.63 & 9.54 & 9.38 \\
\hline Mean.. & & 9.43 & 9.48 & 9.61 & 9.51 & 9.30 \\
\hline Deviation from mean (per cent)..... & ... & -.9 & -.3 & +1.0 & .7 & -2.2 \\
\hline
\end{tabular}

In order to determine later the agreement of the measurements on the lamps with those on the screens, percentage deviations from the mean obtained for all lamps at each voltage are given in Fig. I, and the representative curve for each laboratory is drawn. The points at which the screens fall (i. e., the approximate voltage to which a tungsten test lamp would have to be set to obtain a color match with the screen removed) are indicated by the vertical $50239^{\circ}-16-9$ 
dotted lines which intersect the curves of this figure. Correction to the mean value of the transmission of each screen may now be assigned from a consideration of the percentage difference on the lamps, as shown in the figure at the intersection with the corresponding vertical line. There is thus obtained for the screens a relation among the laboratories corresponding to that given by the curves for the lamps over the range covered by the screens.

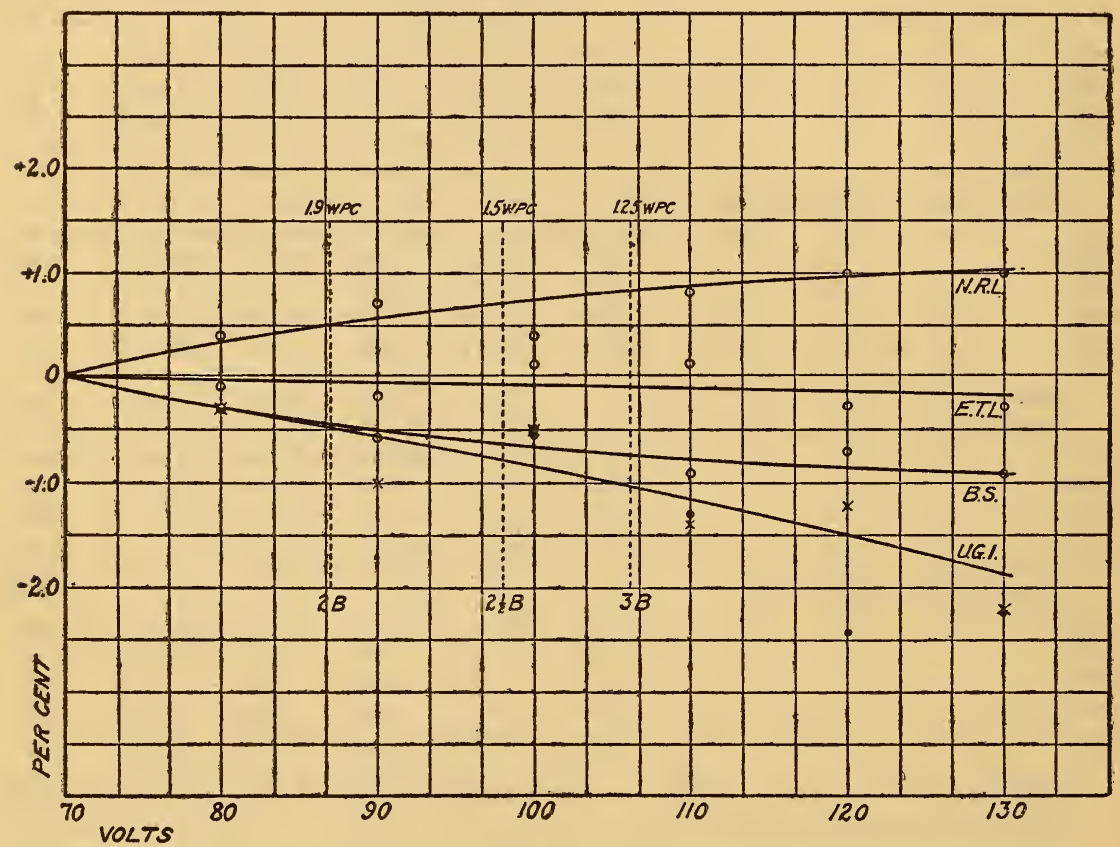

FIG. I.-Values on the lamps expressed as differences from the mean obtained by the three laboratories using Lummer-Brodhun photometers. The dots at IOO, IIO, I2O, and I3O volts represent flicker values found by Crittenden and Richtmyer. (See Section VI.)

\section{COMPARISON OF RESULTS ON LAMPS AND SCREENS}

The values obtained for the glasses by direct measurement and those by computation (see Sec. V) from the results on the lamps are compared in Table 9. In the last four columns of the lower half of the table are the differences between these two sets of values. It is to be noted that for the three laboratories using the Lummer-Brodhun photometer the differences average about 0.2 per cent on the mean of the three glasses. That is, each laboratory was remarkably consistent in the two series of measurements. 
TABLE 9

Comparison of Observed and Computed Values on the Screens

\begin{tabular}{|c|c|c|c|c|c|c|c|c|}
\hline & & & & \multicolumn{5}{|c|}{ Values of screens as observed } \\
\hline \multicolumn{4}{|c|}{ Screens } & B. S. & E.T. L. & N.R. L. & Mean & U. G.I. \\
\hline \multirow{4}{*}{\multicolumn{4}{|c|}{ 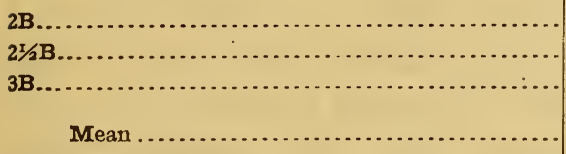 }} & 0.653 & 0.657 & 0.659 & 0.656 & 0.646 \\
\hline & & & & .584 & .585 & .588 & .586 & .579 \\
\hline & & & & .537 & .542 & .543 & .541 & .529 \\
\hline & & & & .591 & .595 & .597 & .594 & .585 \\
\hline \multirow{2}{*}{ Screens } & \multicolumn{4}{|c|}{$\begin{array}{l}\text { Relative values as computed from } \\
\text { measurements on lamps }\end{array}$} & \multicolumn{4}{|c|}{$\begin{array}{l}\text { Differences, computed values from } \\
\text { observed values }\end{array}$} \\
\hline & B. S. & E.T. L. & N. R. L. & U. G. I. & B. S. & E.T. L. & N.R.I. & U. G. I. \\
\hline $2 B$. & 0.653 & 0.6555 & 0.6595 & 0.6525 & 0.000 & +0.0015 & -0.0005 & -0.0065 \\
\hline $2^{1} / 2 \mathrm{~B}$ & .5825 & .5855 & .5905 & .5815 & +.0015 & -.0005 & -.0025 & -.0025 \\
\hline 3B................ & .537 & .5405 & .5455 & .5355 & .000 & +.0015 & -.0025 & -.0065 \\
\hline Mean.. & .591 & .594 & .5985 & .590 & .0005 & .0012 & .0018 & .0052 \\
\hline
\end{tabular}

In regard to the flicker values, it appears that the somewhat greater differences between the results on the glasses and the lamps is due to the values assigned to the former. As further evidence of this fact, the results by Crittenden and Richtmyer ${ }^{\circ}$ on two of the lamps (Nos. 2865 and 2866), using color screens calibrated by means of a flicker photometer, agree very closely, except at ${ }^{2} 20$ volts, ${ }^{7}$ with those reported by the U. G. I., their values being indicated by dots in Fig. $\mathrm{I}$. On the other hand, the results given by the same authors for the screens by the flicker method do not agree so well with the U. G. I. values here reported.

The differences given in this table show that the first three laboratories mentioned are consistent in their measurements on the lamps and screens to within less than 0.2 per cent on the average, and that the U. G. I. computed value is practically the same as that of the Bureau of Standards.

\section{ADDITIONAL CHECK MEASUREMENTS}

In order to secure a further check of the ratio of the values obtained by the Nela Research Laboratory and the Bureau of Standards, arrangements were made whereby F. E. Cady, through

\footnotetext{
6 Trans. I. E. S., 11, p. 33I, I9x6.

7 These authors state that this value should not be given equal weight with the others because only one lamp was measured at this voltage.
} 
the courtesy of Dr. Hyde, came to the Bureau and made a number of comparative measurements with the Bureau's observers who took part in this intercomparison.

Comparative measurements were first made of the ratio $\mathrm{Y} / \mathrm{B}$ and of the transmission of a glass screen $(3 \mathrm{G})$ using the ficker photometer. (See next section.) In these measurements the B. S. observers checked their former values to within the errors of observation, and hence their values in this test are not here given. Following this test, one of the lamps (No. 266I) used in establishing the voltage-candlepower curve for tungsten lamps was measured at 106 volts in terms of its value at 70 volts using a Lummer-Brodhun photometer. At the latter voltage the color of this lamp was the same as that of a 4-wpc carbon and at the upper voltage the color corresponded to that produced by glass 3B when used with a 4-wpc carbon lamp. The comparison lamp was adjusted for color match with No. 266r at 70 volts, and the illumination on the photometer screen was adjusted to ro metercandles as in all the previous measurements made at the Bureau in this intercomparison. Three series of determinations of the ratio of candlepower at the two voltages were made by five observers, including Mr. Cady, and all settings were made by the contrast principle as was done in all the previous measurements at the Bureau. These results, together with the values previously obtained for 3 B by these five observers (see Table 5), each in his own laboratory, are given in Table 10.

TABLE 10

Comparison of Check Measurements

\begin{tabular}{|c|c|c|c|c|c|}
\hline Observers & Series 1 & Series 2 & Series 3 & Mean & $\begin{array}{c}\text { Trans- } \\
\text { mission } \\
\text { of } 3 B \text {, } \\
\text { from } \\
\text { Table } 5\end{array}$ \\
\hline F. E. C... & 4. 90 & 4.92 & 4.91 & 4.91 & 0.547 \\
\hline G.W.M.............. & 4. 85 & 4.87 & 4. 81 & 4.85 & .542 \\
\hline J.F.S.............. & 4. 79 & 4.84 & 4.81 & 4.81 & .538 \\
\hline 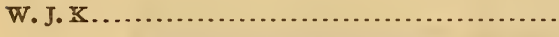 & 4. 80 & 4.81 & 4. 73 & 4. 78 & .534 \\
\hline 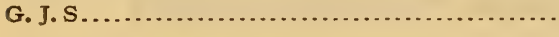 & 4. 80 & 4. 76 & 4. 73 & 4.77 & .536 \\
\hline Mean of the four B. S. observers........... & 4.81 & 4. 82 & 4. 77 & 4.80 & $.537_{5}$ \\
\hline Value from B. S. voltage-candlepower curve..... & …. & 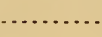 & ..... & 4.81 & .538 \\
\hline
\end{tabular}


A comparison of the last two columns shows that, for the lamp, the percentage difference between the value of Mr. Cady and the mean of the B. S. observers is practically the same as for the screen, although the latter was measured under considerably different conditions of illumination in the two laboratories. As the color step was the same in each case, it can be reasonably concluded from this check that the indicated small difference between the two laboratories is real and is due, at least in a great measure, if not entirely, to a difference in the characteristics of the two groups of observers. In this connection it is of interest to note that if, in either laboratory, the first half of the observers, in the order given in Table 5, be arbitrarily taken as one group and the other half as a second group, the difference between the value by the two groups in either laboratory is comparable with the difference between the laboratories themselves.

It is obvious, therefore, that all measurements involving a color difference should be left as much as possible to the standardizing laboratory where the observers should be carefully selected, their relation to normal determined, and, if necessary, corrections made to their observations.

\section{CHARACTERISTICS OF THE BUREAU OF STANDARDS' OBSERVERS}

In the investigation by Crittenden and Richtmyer, referred to in Section VI, the observers who took part in this intercomparison determined, with the flicker photometer, a value for the ratio of the Ives-Kingsbury yellow and blue solutions, ${ }^{8}$ and also a value for the transmission of glass screen $3 \mathrm{G}$. These values, together with the values obtained with the Lummer-Brodhun photometer for glass screen $3 \mathrm{~B}$ (Table 5 , direct method), which had about the same color density as $3 \mathrm{G}$, are given in Table II. In this table are included also the mean values by the II4 observers used by Crittenden and Richtmyer, the values by Mr. Cady, and those by Dr. C. H. Sharp and Dr. H. E. Ives, who were observers in their respective laboratories and who visited the Bureau and made their measurements during the progress of the above investigation by Crittenden and Richtmyer. 
TABLE 11

Data on Observers

\begin{tabular}{|c|c|c|c|c|c|c|}
\hline \multirow[b]{2}{*}{ Observers } & \multirow{2}{*}{$\begin{array}{l}\text { Ratio } \\
\mathbf{Y} \div \mathbf{B}\end{array}$} & \multicolumn{2}{|c|}{ Transmission } & \multicolumn{2}{|c|}{$\begin{array}{l}\text { Deviations from averaze } \\
\text { of } 114 \text { observers }\end{array}$} & \multirow{2}{*}{$\begin{array}{l}\text { Difference } \\
\text { between } \\
\text { deviations }\end{array}$} \\
\hline & & $\begin{array}{c}\text { 3G. } \\
\text { Flicker } \\
\text { photometer }\end{array}$ & $\begin{array}{c}\text { 3B. } \\
\text { Lummer- } \\
\text { Brodhun } \\
\text { photometer }\end{array}$ & $\begin{array}{c}\text { Flicker } \\
\text { photometer }\end{array}$ & $\begin{array}{c}\text { Lummer- } \\
\text { Brodhun } \\
\text { photometer }\end{array}$ & \\
\hline G. W. M. (B. S.). & 1.025 & 0.540 & 0.542 & -0.003 & +0.008 & +0.011 \\
\hline J. F. S. (B. S.) ................. & 1.103 & .534 & .538 & -.009 & +.004 & +.013 \\
\hline B. M. (B.S.) $\ldots \ldots \ldots \ldots$ & 1.120 & .532 & .526 & -.011 & -.008 & +.003 \\
\hline H. B. S. (B. S.).... & .822 & .559 & .552 & +.016 & +.018 & +.002 \\
\hline W. J. K. (B. S.) . ........... & .968 & .540 & .534 & -.003 & .000 & +.003 \\
\hline W. H. V. (B. S.) .. & .948 & .548 & .535 & +.005 & +.001 & -.004 \\
\hline A. H. T. (B. S.).... & 1.014 & .542 & .535 & -.001 & +.001 & +.002 \\
\hline G. J. S. (B. S.) . . . . . . . & .998 & .540 & .536 & -.003 & +.002 & +.005 \\
\hline Means.. & 1.000 & .542 & .537 & -.001 & +.003 & +.004 \\
\hline F. E. C. (N. R. L.)... & 1. 044 & .536 & .547 & -.007 & +.013 & +.020 \\
\hline C. H. S. (E. T. L.)...... & 1.058 & .534 & .537 & -.009 & +.003 & +.012 \\
\hline H. E. I. (U. G. I.)....... & .951 & .542 & .540 & -.001 & +.006 & +.007 \\
\hline Average of 114 observers...... & .99 & .543 & .534 & 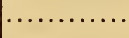 & 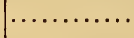 & (........ \\
\hline
\end{tabular}

It is to be noted that, although there is considerable variation in the ratio $\mathrm{Y} / \mathrm{B}$ among the different individuals of the Bureau's group of eight observers, the mean of all is remarkably close to the characteristic ratio (0.99) found by Crittenden and Richtmyer for the average of I 4 observers. Hence, as is evident from the results on $3 \mathrm{G}$, a mean value obtained by this group with a flicker photometer would require practically no correction to obtain a value corresponding to that by the average eye.

A comparison of the values on $3 \mathrm{~B}$ shows that this group is very close to the average of the I 4 observers also in its results with the Lummer-Brodhun photometer, although not quite so close as with the flicker. Whether this slightly greater variation arises from the fact that in the average eye work of Crittenden and Richtmyer the illumination was higher than in this investigation, or that in the former the photometer was used as an equality rather than as a contrast field, or (as is more likely) from the greater uncertainty of the Lummer-Brodhun photometer, is difficult to say. However, as is shown by the differences between deviations and better by means of a plot between values of $\mathrm{Y} / \mathrm{B}$ and transmission (Fig. 2), all the individuals of this group do not have, with respect to the average of the II4, the same relation with the Lummer-Brodhun photometer as they do with the flicker, the first two being decidedly different by the two methods. 
Now it is found that if these two observers be omitted the mean of the other six with a flicker photometer is just as close to normal as the whole group, their mean flicker values for $3 \mathrm{G}$ and $\mathrm{Y} / \mathrm{B}$ being 0.5435 and 0.98 , respectively; and, further, their mean LummerBrodhun value for $3 \mathrm{~B}$ is more nearly equal to the average eye value (0.534), being 0.536 instead of 0.537 , as found by the whole group. It would appear, therefore, that in order to make a comparison of former B. S. values with present (average eye) values, as is done below, there is perhaps some advantage in using the mean of this "selected" group of six.

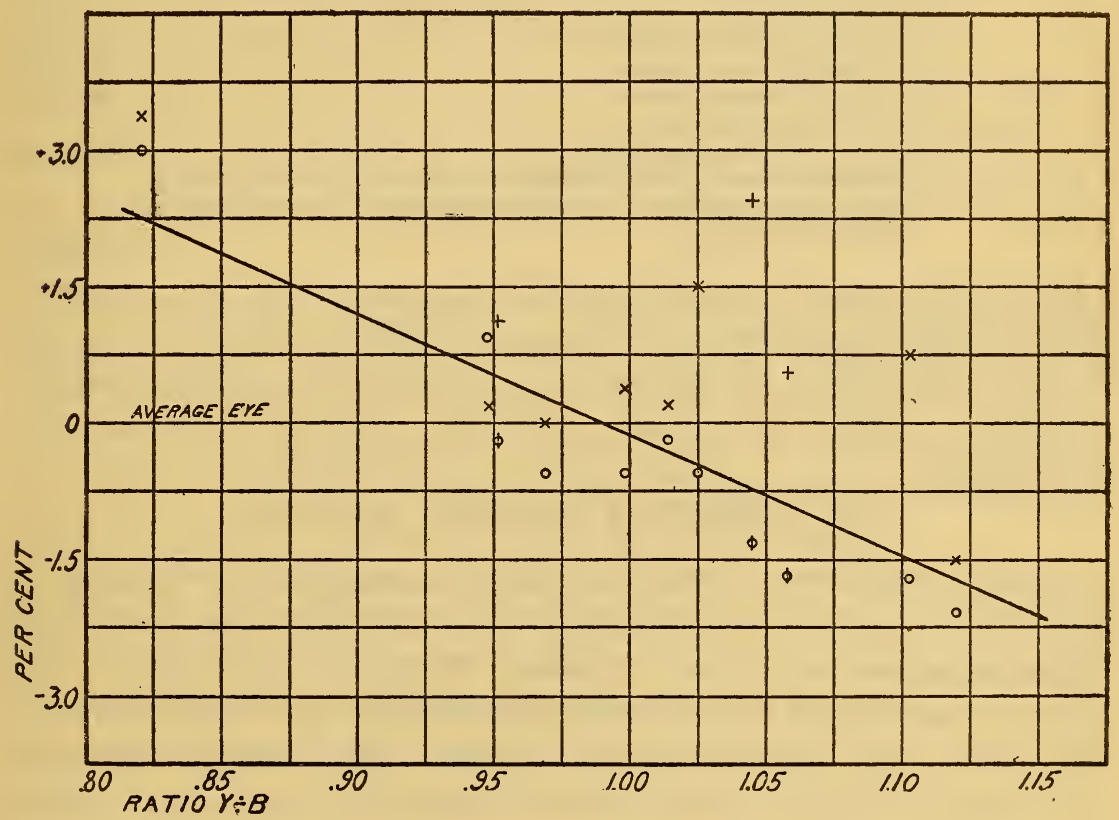

Frg. 2.-This is a plot of the values given in Table II. The ordinates are values of transmission expressed as differences in per cent from the corresponding average value obtained by II4 observers. Lummer-Brodhun values by the eight B. S. observers are represented by X's and their ficker values by o's. The corresponding values by the three observers from the outside laboratories are represented by +'s and $\phi$ 's, respectively. The curve represents the flicker data obtained by the II4 observers.

Further checks on the value of $3 B$ from the present investigation as well as from the investigation of Crittenden and Richtmyer, who determined values for $3 \mathrm{G}$, which was found to be $\mathrm{I} .6$ per cent higher than $3 \mathrm{~B}$, are given in the following table. Nearly all of the 20 observers selected by Crittenden and Richtmyer from the II 4 had considerable photometric experience, and they were well distributed with respect to the average eye characteristic as determined with a flicker photometer. 
TABLE 12

\section{Comparison of Values by Different Methods and also by Different Groups of Observers}

I. With the Lummer-Brodhun photometer:

A. As found in Crittenden and Richtmyer's investigation-

1. By 114 observers selected at random from the Bureau of Standards scientific

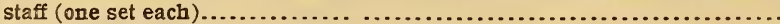

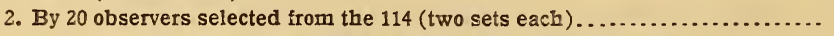

3. By 14 most consistent observers selected from the 20 (two sets each)

B. As found in this intercomparison-

1. By 8 observers............................................. $3 \mathrm{~B}=0.537$

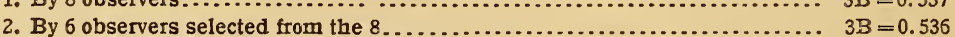

A. As found in Crittenden and Richtmyer's investigation-

1. By 114 observers (same as above) ............................... $3 B=0.534$

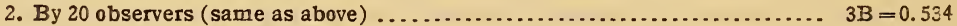

3. By 14 observers (same as above) .................................... $3 B=0.534$

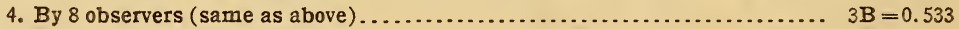

5. By 6 observers (same as above) ............................... $3 B=0.534$

B. As. found in this intercomparison-

1. By U. G. I., direct measurement................................ $3 B=0.529$

2. By computation from U. G. I. measurements on lamps with the LummerBrodhun photometer and a Crova solution calibrated by a method involving the ficker photometer.................................... $3 B=0.536$

From the above comparison it is apparent that for the color difference here represented the group of eight, as well as the group of six, is as nearly normal as it is possible for a small group to reproduce average eye values with the respective photometers mentioned.

\section{CHECK OF FORMER VALUES}

Screen $2 / 2 \mathrm{~B}$ was chosen for this intercomparison because it had approximately the same color value as the glasses used in the intercomparison with the National Physical Laboratory. The mean values found for this screen by the group of eight and by the group of six were 0.5836 and 0.5828 , respectively. The relative value of $2 \frac{1}{2} \mathrm{~B}$ to $3 \frac{1}{2} \mathrm{C}$, which is one of the glasses used in the B. S.-N. P. L. intercomparison, has been recently determined and found to be as follows:

$$
3 \frac{1}{2} \mathrm{C}=21 / 2 \mathrm{~B}+0.010
$$

Therefore, by the group of 8 observers........... $31 / 2 \mathrm{C}=0.5^{8} 36+0.010=0.5936$ And by the group of 6 observers................ $3^{1 / 2} \mathrm{C}=0.5828+0.010=0.5928$ Value used in the B. S.-N. P. L. intercomparison in Igrr.............. 0. 5924

Although in the earlier measurements made by the Bureau of Standards no method of selection of observers was employed and the illumination used was that employed in other work done at the Bureau and was much lower than that used in the recent investigation of Crittenden and Richtmyer, nevertheless it appears from the agreement in the above values that the considerable deviations from the mean of some of the observers at that time were such that the plus and minus deviations substantially coun- 
terbalanced each other, and the figures then obtained by the Bureau with the Lummer-Brodhun photometer correspond closely to those now obtained by an average eye working under the higher illumination used by the investigators mentioned. Of course, it would not be expected that such deviations would all be in one direction, but that they were averaged out so completely was a matter of good fortune.

\section{CONCLUSION}

The results of this intercomparison show quite conclusively that in each laboratory, regardless of the kind of photometer used, even though a considerable color difference was involved, each observer maintained a fairly constant criterion with respect to the mean. The same is true of each laboratory in respect to its relation to the mean of all, as judged by the measurements on the glass screens and those made on the lamps some months afterward.

Considering the difficulties involved in the measurements, the different characteristics of observers and the wide difference in illumination employed, covering probably a range of ten times, the agreement among the laboratories must be considered remarkably good. It is true, however, that although the differences are small they are not negligible in precision photometry.

It is evident, therefore, that measurements to establish standards involving a color difference should be left as much as possible to the standardizing laboratory where the observers must be carefully selected and a considerable number employed and the kinds of instruments and the conditions of illumination, etc., definitely fixed.

An examination of the Bureau's observers who took part in this work shows that their mean characteristic is very approximately the same as that of the "average eye," as determined from a test of II4 observers taken at random from the Bureau's scientific staff.

Further evidence is obtained as to the accuracy of the values assigned to a group of I.5-wpc tungsten standards used in a previous intercomparison with the National Physical Laboratory of England.

The authors express the Bureau's appreciation of the cooperation of the laboratories, and of those who represented them, in carrying out this investigation.

WASHINGTON, January 22, I9I6. 